\title{
Brain stem auditory evoked potentials in patients with multiple system atrophy with progressive autonomic failure (Shy-Drager syndrome)
}

\author{
DEEPAK PRASHER,* ROGER BANNISTER \\ From the Medical Research Council Neuro-Otology Unit, Institute of Neurology* and the National Hospital for \\ Nervous Diseases, London, UK
}

SUMMARY Brain stem potentials from three groups of patients, namely those with pure progressive autonomic failure, Parkinson's disease and multisystem atrophy with progressive autonomic failure (Shy-Drager syndrome) were compared with each other and a group of normal subjects. In virtually all the patients with multisystem atrophy with progressive autonomic failure the brain stem potentials were abnormal in contrast to normal findings with Parkinson's disease. The closely associated group of patients with progressive autonomic failure alone also revealed no abnormalities of the BAEP. This separation of the two groups, Parkinson's disease and progressive autonomic failure from multisystem atrophy with progressive autonomic failure is important clinically as multiple system atrophy of the Shy-Drager type has extra-pyramidal features closely resembling Parkinsonism or a late onset cerebellar degeneration. From the abnormalities of the brain stem response in multisystem atrophy with progressive autonomic failure, it is clear that some disruption of the auditory pathway occurs in the ponto-medullary region as in nearly all patients there is a significant delay or reduction in the amplitude of components of the response generated beyond this region. The most likely area involved is the superior olivary complex.

Brain stem auditory evoked potentials (BAEPs) occur within 10 milliseconds of stimulus onset and represent a series of neural events occurring along the ascending auditory pathway. A normal response, shown in fig 1 , consists of a series of waves with vertex-positive peaks which are numbered sequentially in Roman numerals. ${ }^{1}$ As a result of experimental lesions in cats ${ }^{23}$ and pathological evidence from humans ${ }^{4-7}$ each of the BAEP waves has been considered to represent the activity from the auditory nerve (wave I), cochlear nucleus (wave II) at the medullopontine junction, superior olivary complex (wave III) in the caudal pons, lateral lemniscus (wave IV) and the inferior colliculus (wave V) in the mid brain. However, more recently it has been shown by animal experiments ${ }^{89}$ that each nucleus is likely to contribute to more than one wave in the BAEP, but the extrapolation of cat data to explain human BAEP generation remains open to question. ${ }^{10}$

The brain stem responses provide an easy and non-

Address for reprint requests: Dr DK Prasher, MRC Neuro-Otology Unit, Institute of Neurology, Queen Sq, London WCIN 3BG, UK

Received 1 March 1985 and in revised form 1 July 1985. Accepted 6 July 1985 invasive means of assessing the integrity of brain stem function and indeed have been useful in detecting subclinical lesions of the brain stem, for example in

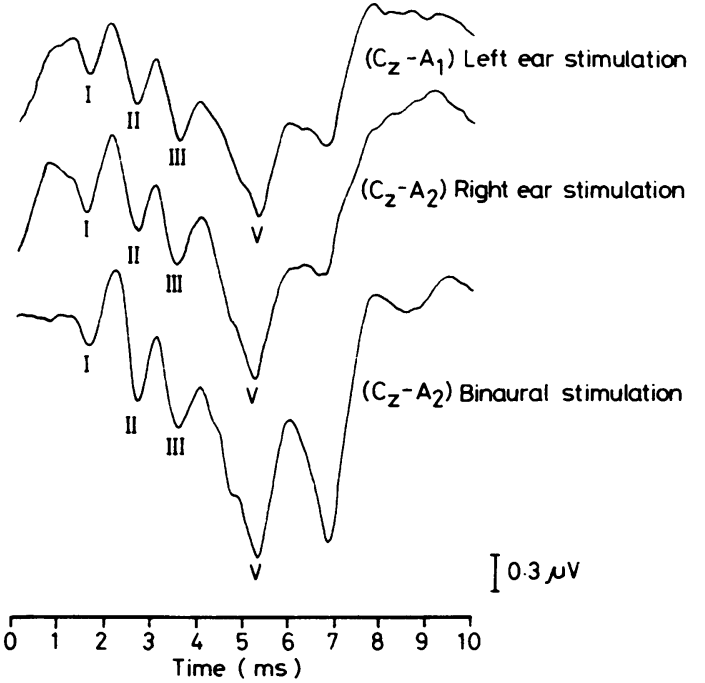

Fig 1 Normal brain stem response to monaural and binaural stimulation. 
Table 1 Group composition

\begin{tabular}{lllll}
\hline Groups tested & Male & Female & Age range & Mean age $(y)$ \\
\hline Normals $\mathrm{n}=32$ & 12 & 20 & $20-56$ & 44 \\
Parkinson's disease $\mathrm{n}=20$ & 13 & 7 & $41-69$ & 58 \\
Progressive autonomic failure $\mathrm{n}=6$ & 3 & 3 & $51-55$ & 53 \\
$\begin{array}{l}\text { Multiple system atrophy with progressive autonomic failure } \\
\text { (Shy-Drager syndrome) } \mathrm{n}=14\end{array}$ & 9 & 5 & $43-71$ & 59 \\
\hline
\end{tabular}

Table 2 Pathology in groups tested

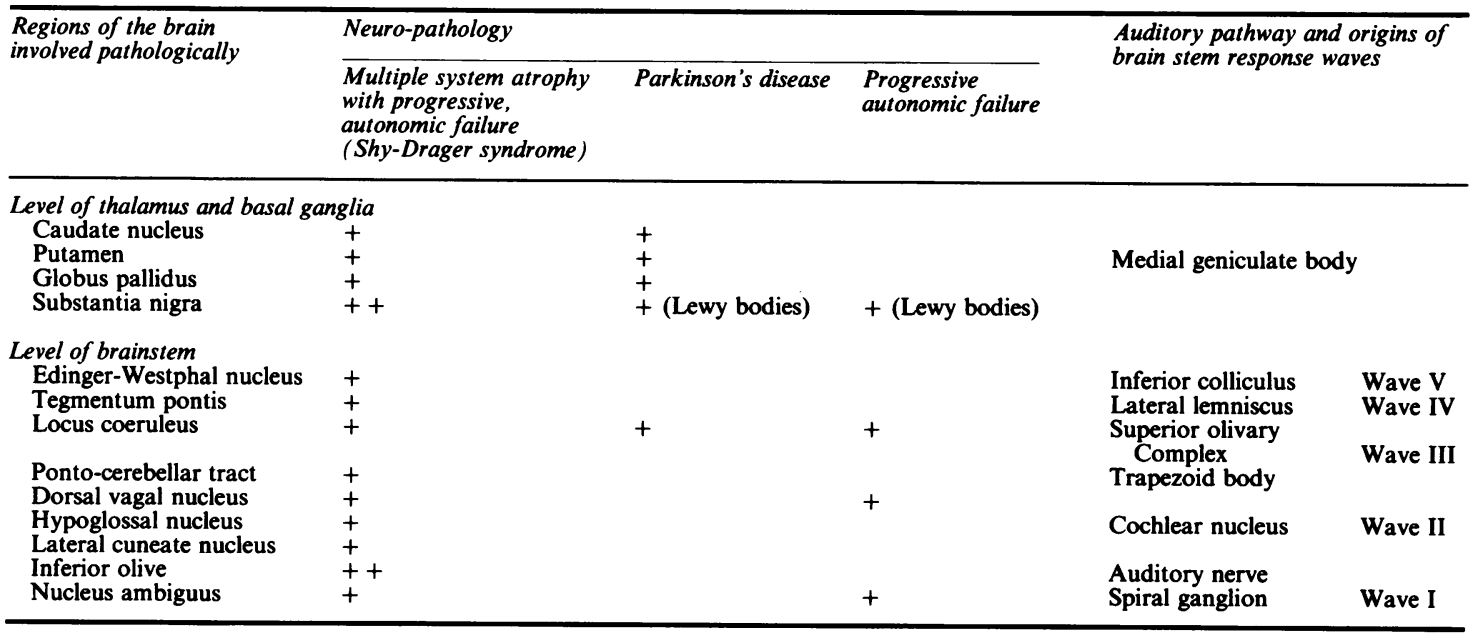

patients with multiple sclerosis. ${ }^{1112}$ Abnormalities of the BAEP have also been reported in heredodegenerative diseases such as Friedreich's ataxia ${ }^{13}$ and Charcot-Marie-Tooth disease. ${ }^{14}$

There are conflicting reports at present regarding the brain stem responses in Parkinson's disease. Gawel $e t$ al $^{15}$ reported prolongation of the latency of wave $\mathrm{V}$ without any effect on its amplitude but Kriss (personal communication) was unable to confirm these findings in a large group of patients. Tsuji et al ${ }^{16}$ and Chiappa ${ }^{17}$ also report normal BAEPs in patients with Parkinson's disease.

Similar anomalies exist with the visual evoked potential (VEP) in that Bodis-Wollner et $a l^{18}$ and Gawel et $a^{15}$ reported VEP abnormalities in Parkinson's disease whilst others ${ }^{1920}$ have been unable to confirm this. In this study, brain stem potentials from three different groups of patients, namely those with progressive autonomic failure, Parkinson's disease and multiple system atrophy with progressive autonomic failure (Shy-Drager syndrome) were compared with each other and with a group of normal subjects. The main aim of the study was (a) to evaluate the usefulness of brain stem potentials in differentiating between patients in the groups especially those with Parkinson's disease from those with multisystem atrophy with progressive autonomic failure and (b) to relate the extent of the brain stem involvement by the disease in particular patients with the abnormalities of the brain stem potentials.

\section{Methods}

The brain stem potentials were recorded with conventional EEG silver/silver chloride disc electrodes placed at the vertex $(\mathrm{Cz})$ and upon each mastoid. The ground electrode -was placed at the chin. Responses from $\mathrm{Cz}-\mathrm{A} 1$, and $\mathrm{Cz}-\mathrm{A} 2$ were recorded to ipsilateral, contralateral and binaural stimulation. The patient sat in a comfortable reclining chair in a sound-proof chamber and listened through TDH 39 earphones to clicks (rectangular pulses of $100 \mu \mathrm{s}$ electrical duration) at an intensity level of $90 \mathrm{~dB}$ SL presented at a rate of $10 \mathrm{~Hz}$. The electrical activity was amplified $\left(\times 10^{5}\right)$, filtered $(3 \cdot 2 \mathrm{~Hz}$ to $3 \cdot 2 \mathrm{kHz})$, digitised every $10 \mu \mathrm{s}$ for 1024 points giving an analysis window of $10.24 \mathrm{~ms}$. A total of 1024 stimulus presentations were made for each average. The latencies of the waves were measured with a cursor under program control. Responses were obtained twice for each configuration in order to check the replicability. Four of the 14 patients with multisystem atrophy with progressive autonomic failure were retested after 2-6 months in order to check whether the response abnormalities were consistent or otherwise, over a period of time. The analysis of the BAEP recordings was restricted to waves I, III and V as these are 
Table 3 Clinical features

\begin{tabular}{|c|c|c|c|c|c|c|c|c|c|c|}
\hline $\begin{array}{l}\text { Case } \\
\text { No. }\end{array}$ & $\begin{array}{l}\text { Name } \\
\text { age }(y) \\
\text { sex }\end{array}$ & $\begin{array}{l}\text { Duration of } \\
\text { symptoms }(y)\end{array}$ & $\begin{array}{l}\text { Postural } \\
\text { hypotension }\end{array}$ & $\begin{array}{l}\text { Defective } \\
\text { sweating }\end{array}$ & $\begin{array}{l}\text { Urinary } \\
\text { symptoms }\end{array}$ & Impotence & Parkinsonism & Pyramidal & $\begin{array}{l}\text { Cerebellar } \\
\text { signs }\end{array}$ & $\begin{array}{ll}\text { Diagnosis } & \mathbb{D} \\
\text { signs } & \stackrel{\bar{C}}{0} \\
& \text { क }\end{array}$ \\
\hline 1 & $\begin{array}{l}\text { DG } \\
60 \\
M\end{array}$ & 3 & + & + & ++ & + & + & + & + & $\mathbf{M S A}+$ PAA \\
\hline 2 & $\begin{array}{l}\text { TR } \\
64 \\
M\end{array}$ & 3 & + & + & ++ & + & + & + & ++ & $\begin{array}{l}\text { MSA (OPCA } \\
\quad+\text { PAF }\end{array}$ \\
\hline 3 & $\begin{array}{l}\text { DW } \\
59 \\
\text { M }\end{array}$ & 10 & + & + & ++ & + & ++ & + & + & MSA + PAE \\
\hline 4 & $\begin{array}{l}\text { FF } \\
64 \\
M\end{array}$ & 5 & ++ & + & + & + & + & + & + & $\mathbf{M S A}+\mathbf{P A \overline { F }}$ \\
\hline 5 & $\begin{array}{l}\text { GS } \\
43 \\
F\end{array}$ & 8 & ++ & + & + & $*$ & ++ & + & + & $\mathrm{MSA}+\mathrm{PA} \frac{\overline{\overline{\mathrm{Q}}}}{\frac{\overline{\bar{T}}}{\bar{\Phi}}}$ \\
\hline 6 & $\begin{array}{l}\text { DE } \\
71 \\
F\end{array}$ & 4 & + & + & + & * & + & + & + & $\mathrm{MSA}+\mathrm{PAB}$ \\
\hline 7 & $\begin{array}{l}\mathrm{PP} \\
44 \\
\mathrm{M}\end{array}$ & 9 & ++ & - & ++ & + & ++ & + & + & MSA + PAF \\
\hline 8 & $\begin{array}{l}\text { BA } \\
61 \\
F\end{array}$ & 7 & + & + & + & $*$ & - & + & ++ & $\mathbf{M S A}+\mathbf{P}$ \\
\hline 9 & $\begin{array}{l}\text { MW } \\
62 \\
\text { F }\end{array}$ & 2 & + & + & ++ & * & + & + & - & $\underset{\text { atypical }}{\mathrm{MSA}}+\mathrm{PA}$ \\
\hline 10 & $\begin{array}{l}\mathrm{KP} \\
56 \\
\mathrm{~F}\end{array}$ & 3 & ++ & + & + & * & - & + & + & $\begin{array}{l}\text { MSA (OPCA } \\
\text { + PAF }\end{array}$ \\
\hline 11 & $\begin{array}{l}\text { LA } \\
53 \\
\text { M }\end{array}$ & 4 & + & + & + & + & + & + & ++ & 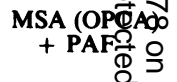 \\
\hline 12 & $\begin{array}{l}\text { JW } \\
64 \\
M\end{array}$ & 4 & + & + & + & + & + & + & - & MSA + P्र् \\
\hline 13 & $\begin{array}{l}\text { JM } \\
71 \\
\text { M }\end{array}$ & 9 & + & + & + & - & - & + & ++ & $\begin{array}{l}\text { MSA (OPPAळ } \\
\text { + PAF }\end{array}$ \\
\hline 14 & $\begin{array}{l}\text { DR } \\
62 \\
M\end{array}$ & 10 & + & + & + & + & + & + & - & 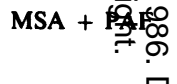 \\
\hline
\end{tabular}

Key:

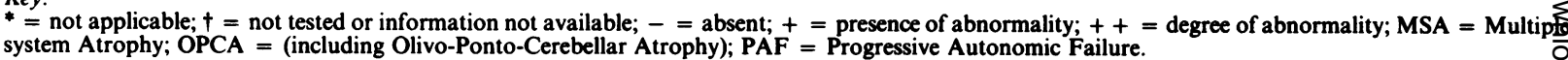

the most reliable components of the response recorded in both normals and patients.

\section{Patients}

Three groups of patients and a normal control group of 32 subjects were examined for this study. The patient groups comprised 20 patients with Parkinson's disease, six with pure progressive autonomic failure and 14 with multiple system atrophy with progressive autonomic failure (Shy- Drager syndrome) were tested. All patients with Parkinson's disease were on conventional anti-Parkinsonian therapy (either Sinemet, Madopar or Artane or a combination of these) and were only tested when on treatment. Details of each group in terms of sex ratio, mean age and range are given in table 1 . The neuro-pathological involvement of various levels of the neurological system in the diseases considered for this study are illustrated in table 2 together with the auditory pathway and the origins of the various components of the brain stem response along that pathway. It can be seen in table 2 that the regions of the nervous system involved in Parkinson's disease overlap with those involved in multiple system atrophy with progressive autonomic failure. However the auditory pathway does not appear to be involved directly in either condition but several brain stem nuclei are affected by both Parkinson's disease and multisystem atrophy with progressive autonomic failure. The clinical features of the patients with multisystem atrophy with progressive autonomic failure are summarised in table 3, which also

Table 4 BAEP abnormalities in groups tested

\begin{tabular}{lllr}
\hline BAEPs & $\begin{array}{l}\text { Parkinson's } \\
\text { disease }\end{array}$ & $\begin{array}{l}\text { Progressive } \\
\text { autonomic } \\
\text { failure }\end{array}$ & $\begin{array}{l}\text { MSA } \\
\text { with } \\
P A F\end{array}$ \\
\hline $\begin{array}{l}\text { Normal } \\
\text { Abnormal in latency }\end{array}$ & $\begin{array}{r}19 / 20 \\
\text { Abnormal in amplitude }\end{array}$ & $6 / 6$ & $1 / 14$ \\
$\quad$ Ratio of Wave V/I & $1 / 20$ & $0 / 6$ & $11 / 14$ \\
\hline
\end{tabular}


Table 5 BAEP latencies in groups tested

\begin{tabular}{|c|c|c|c|c|c|}
\hline BAEPS & & $\begin{array}{l}\text { Normals } \\
n=32(\text { mean } \pm S D)\end{array}$ & $\begin{array}{l}\text { Parkinson's disease } \\
n=20(\text { mean } \pm S D)\end{array}$ & $\begin{array}{l}\text { Prog. autonomic failure } \\
n=6(\text { mean } \pm S D)\end{array}$ & $\begin{array}{l}M S A+P A F \\
\text { (Shy-Drager } \\
\text { syndrome) } \\
n=14 \\
(\text { mean } \pm S D)\end{array}$ \\
\hline $\begin{array}{l}\text { Wave I (ms) } \\
\text { Wave III (ms) } \\
\text { Wave V (ms) }\end{array}$ & $\begin{array}{l}\text { LL } \\
\text { RR } \\
\text { LL } \\
\text { RR } \\
\text { LL } \\
\text { RR }\end{array}$ & $\begin{array}{l}1.70 \pm 0.12 \\
1.71 \pm 0.12 \\
3.82 \pm 0.21 \\
3.80 \pm 0.22 \\
5.67 \pm 0.19 \\
5.68 \pm 0.20\end{array}$ & $\begin{array}{l}1.77 \pm 0.23 \\
1.72 \pm 0.25 \\
3.87 \pm 0.25 \\
3.89 \pm 0.27 \\
5.73 \pm 0.24 \\
5.77 \pm 0.26\end{array}$ & $\begin{array}{l}1.77 \pm 0.05 \\
1.77 \pm 0.09 \\
3.70 \pm 0.14 \\
3.68 \pm 0.15 \\
5.65 \pm 0.15 \\
5.67 \pm 0.09\end{array}$ & $\begin{array}{c}1.61 \pm 0.16 \\
1.60 \pm 0.16 \\
3.71 \pm 0.39 \\
3.71 \pm 0.26 \\
* 6.13 \pm 0.60 \\
* 6.06 \pm 0.58\end{array}$ \\
\hline
\end{tabular}

Key:

${ }^{*}=\mathrm{p}<0.1$; BAEPs $=$ Brain stem Auditory Evoked Potentials; $\mathbf{L L}=$ Left stimulation and recording; $\mathbf{R} \mathbf{R}=\mathbf{R i g h t}$ stimulation and recording.

indicates the duration of symptoms for all patients studied in that group. None of the patients had any symptomatic hearing impairment, although two of the patients with multisystem atrophy with progressive autonomic failure and three with Parkinson's disease had a slight high-frequency loss consistent with their age. The presence of a hearing loss due to presbycusis does not affect the interwave latency intervals of the BAEP. Only one patient (MW) was atypical of the group in having some psychological impairment.

\section{Results}

A comparison of the findings of the brain stem potentials between the normal control group and the three groups of patients is shown in table 4 .

Thirteen of the 14 patients with multisystem atrophy with progressive autonomic failure had an abnormal brain stem response despite any symptomatic auditory deficit. This was in contrast to only 1 of the 20 patients with Parkinson's disease showing any abnormality of the brain stem potentials. None of the six patients with progressive autonomic failure alone had any abnormal potentials.

In table 5 are shown the latencies of waves I, III and $\mathrm{V}$ on both left mastoid recording $(\mathrm{Cz}-\mathrm{Al})$ with left ear stimulation and right mastoid recording $(\mathrm{Cz}-\mathrm{A} 2)$ with right ear stimulation for all groups including normal subjects. It is clear from this table that the finding of significance is the prolongation of wave $\mathbf{V}$ latency in the group of patients with multisystem atrophy with progressive autonomic failure in contrast to all the other groups. Although the variance of this group is also increased, the FisherBehrens " $d$ " statistic $(d=3.115)$ shows that there is a significant $(p<0.01)$ difference between the normal latency of wave $\mathrm{V}$ and that observed in patients with multisystem atrophy with progressive autonomic failure.

A response was considered abnormal if the latency of any of the waves fell beyond the normal mean by more than two standard deviations on stimulation of either ear. Similarly, if the mean amplitude of wave $\mathrm{V}$ was significantly smaller than that of wave I or III on repeated testing, the response was again considered to be abnormal.

\section{Latency abnormalities}

Using the above criteria, 13 of the 14 patients with multisystem atrophy with progressive autonomic failure were considered to have an abnormality. Wave I which was identified in a large number of the patients (13 of the 14) was within normal latency limits. Wave III was abnormally prolonged in three of the 14 patients. Wave $\mathrm{V}$ was delayed unilaterally in nine patients, with two having wave $\mathrm{V}$ absent contralaterally and the remainder, a normal contralateral wave $V$. In addition, one patient had wave $V$ absent bilaterally, with another having absent wave $\mathrm{V}$ on one side and a normal latency wave $\mathrm{V}$ on the other. Thus 11 of the 14 patients with multisystem atrophy with progressive autonomic failure had an abnormality of wave $\mathrm{V}$ on at least one side. A detailed analysis of the various components of the BAEP for all patients with multisystem atrophy with progressive autonomic failure in terms of the latencies and absolute and relative amplitudes is given in the Appendix.

The central conduction time as measured between wave I and $\mathrm{V}$ was prolonged beyond the normal limit by more than two standard deviations in nine of the 14 patients with multisystem atrophy with progressive autonomic failure and was within normal limits in four of the 14 patients. Of the 11 patients with abnormal responses nine had bilateral abnormalities on both monaural and binaural stimulation. The duration of the symptoms was unrelated to the BAEP findings. The patient with the longest duration of symptoms had a normal response.

\section{Amplitude abnormalities}

The ratio of the mean amplitude of wave $\mathrm{V}$ to wave $\mathrm{I}$ was also used as a criterion for judging the response as it is a more reliable measure than absolute amplitude. It has been observed that wave $V$ is always larger in amplitude than wave $I$ in normals. In this study a ratio of $1.6 \pm 0.2$ was established in the nor- 
Table 6 Ratios in normals and patients

\begin{tabular}{|c|c|c|c|c|}
\hline & Normals & Parkinson's disease & $\begin{array}{l}\text { Progressive autonomic } \\
\text { failure }\end{array}$ & $\begin{array}{l}\text { Multiple system atrophy } \\
+ \text { progressive } \\
\text { autonomic failure }\end{array}$ \\
\hline \multicolumn{5}{|l|}{ Amplitude } \\
\hline Ratio of $\frac{\text { Wave V }}{\text { Wave I }}$ & $1.62 \pm 0.2$ & $1.60 \pm 0.4$ & $1.60 \pm 0.2$ & $1.32 \pm 0.9$ \\
\hline$\frac{\text { Max Binaural Amplitude Wave V }}{\text { Max Monaural Amplitude Wave V }}$ & $1 \cdot 80 \pm 0.3$ & $1.65 \pm 0.3$ & $1.87 \pm 0.3$ & $0.88 \pm 0.5$ \\
\hline
\end{tabular}

mal control group. Using this criterion 13 of the 14 patients with multisystem atrophy with progressive autonomic failure had an abnormal ratio on stimulation of at least one ear, in six of whom the abnormality was bilateral. This is in complete contrast to the normal group and those patients with progressive autonomic failure alone. Of the patients with Parkinson's disease, only one of the 20 had a relatively smaller wave $\mathrm{V}$ than I. Another amplitude criterion which has been found useful ${ }^{20}$ is the ratio of the maximum binaural amplitude of wave $\mathrm{V}$ to the maximum monaural amplitude. In normal subjects wave $\mathrm{V}$ is enhanced by an average of $67 \%{ }^{21}$ on binaural stimulation from the monaural amplitude. Therefore the ratio in normals is $1.80 \pm 0.3$. The values for this ratio across the four groups of patients tested are shown in table 6 which clearly indicates a lack of binaural summation in a majority of the patients with multisystem atrophy with progressive autonomic failure. This is primarily due to the mismatch in latency of wave $V$ recorded from either side of the head.

Overall the amplitudes of all components of the response from patients with multisystem atrophy with progressive autonomic failure were much smaller than those observed in normals. In fig 2 are shown the histograms of the mean amplitude of wave $\mathrm{V}$ for the four groups of subjects tested. It clearly indicates a major reduction in the amplitude of wave $V$ in patients with multisystem atrophy with progressive autonomic failure which is consistent across the patients within this group (indicated by the reduced variance). This reduction in the voltage level of the response and latency prolongation of waves III and/or V coupled with a distorted wave morphology characterised the majority of responses in multisystem atrophy with progressive autonomic failure.

Four patients who were retested after a period of 2-6 months were found to show no significant change in their responses over that period.

Six cases (four patients with multisystem atrophy with progressive autonomic failure, one with pure progressive autonomic failure, one with Parkinson's disease) are presented together with details of the neurological examination and standard investigation in order to assess how these relate to the abnormal brain stem potentials.
Case 1: DG: multisystem atrophy with progressive autonomic failure

A 60-year-old retired civil servant was referred with a 3 year history of difficulty in initiating micturition for which he had a trans-urethral prostatectomy, which did not relieve his symptoms. He had been totally impotent for 3 years and had noticed difficulty with saliva dribbling from the corners of his mouth and poorly perfused hands and feet. Over the same period he noticed difficulty with manipulative skills using his hands and clumsiness of gait which had been getting progressively worse. He had collapsed to the floor several times but had lost consciousness on only one occasion. His voice had been rather monotonous over the last two years. There had also been episodes of hypoxia at night.

The patient had an expressionless face. The facial and pout reflexes were brisk. The left plantar response was flexor and the right equivocal. There was slight cogwheel rigidity at the wrists, more marked on the left than the right. He also had rapidly alternating movements impaired bilaterally.

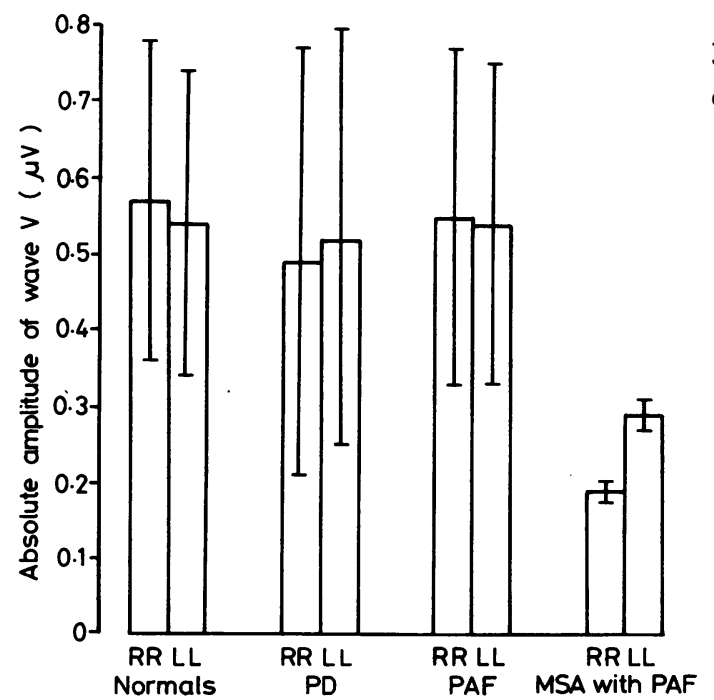

Fig 2 Mean and standard deviation of absolute amplitude of Wave $V$ for the groups tested. ( $P D=$ Parkinson's disease; $P A F=$ Progressive Autonomic Failure; $M S A$ with $P A F=$ multisystem atrophy with progressive autonomic failure). Note the major reduction in the mean and variance of the amplitude of Wave $V$ in MSA with PAF. 

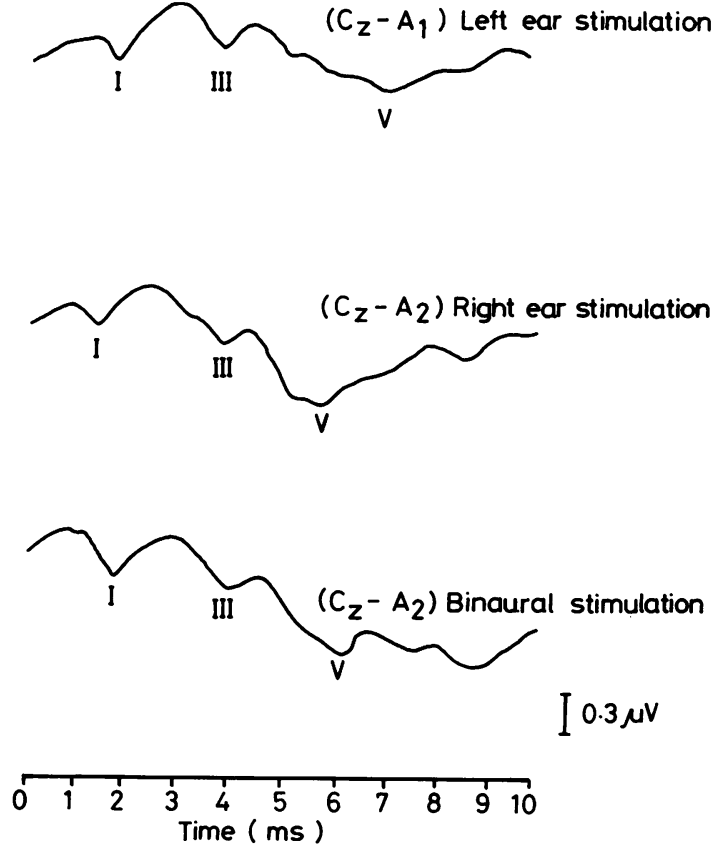

Fig 3 Brain stem responses of Case 1 (MSA with PAF) with bilateral abnormalities more severe on the left.

Fine finger movements were also impaired. There was poor abduction of both vocal cords with the maximum opening about half of the normal range.

Investigations There was a nearly complete sympathetic and parasympathetic cardiac denervation. Sweating was completely absent on heat stress. The patient's blood pressure dropped from $136 / 88 \mathrm{~mm} \mathrm{Hg}$ down to $100 / 78 \mathrm{~mm} \mathrm{Hg}$ on $60^{\circ}$ tilt. A sleep study showed that the patient had an episode of completely obstructive respiration during which his $\mathrm{PO}_{2}$ was $7.45 \mathrm{kPa}(56 \mathrm{~mm} \mathrm{Hg})$ and his $\mathrm{PCO}_{2}$ was 6.45 $\mathrm{kPa}(48 \mathrm{~mm} \mathrm{Hg})$, though later his state stabilised to one of partial upper airways obstruction with improvement in blood gasses.

$B A E P S$ The responses to stimulation of each ear separately and binaurally are presented in fig 3 . The amplitude of all BAEP components were much smaller than those of an age matched control. The latency of wave I relative to the onset of the stimulus was within normal limits for both ears. Wave III was also within normal limits for both ears indicating a normal conduction time between wave I and III. However wave $\mathrm{V}$ was distorted in shape, very small in amplitude relative to wave III and prolonged in latency on left ear stimulation. This indicates a disruption of the electrical activity in the region of the upper pons. Normally wave $\mathrm{V}$ amplitude is very much larger than that of wave I and III. On right ear stimulation, the effect on wave $V$ was only observed in terms of a reduction in its amplitude without any prolongation of latency. There was no abnormal conduction delay on right ear stimulation. On binaural stimulation wave $V$ had both a reduced amplitude and a prolonged latency. The replications of each response were taken after a period of two months with the results being similar to the responses recorded earlier.

Conclusion The brain stem auditory evoked potentials recorded in this patient revealed bilateral abnormalities more severe on the left indicating disruption of conduction in the auditory pathway in the region of the pons.

Case 2: TR: multisystem atrophy (olivo-ponto-cerebellar atrophy) with progressive autonomic failure

A 65-year-old man was referred with a 3 year history of gait disturbance and clumsiness of both legs. He had been impotent for 20 years. He had developed progressive dysarthria with nocturnal stridor. He had marked sphincter disturbance with urgency of micturition and occasional incontinence of urine.

The patient had marked dysphonia and dysarthria suggestive of a spastic speech disturbance. He had a moderately severe symmetrical cerebellar disturbance particularly in the legs. He was very unsteady on walking and there was a marked cogwheel rigidity in both arms and bilateral finger/nose ataxia more marked on the right. Rapidly alternating movements were impaired on the left. Reflexes were preserved in the upper limbs and in the lower limbs the knee jerks were brisk but the left ankle jerk was absent. Both plantar responses were equivocal. The patient had a bilateral vocal cord paralysis.

Investigations Autonomic function tests showed lack of sweating on heat stress, the blood pressure was $192 / 100 \mathrm{~mm}$ $\mathrm{Hg}$ which fell to $162 / 100 \mathrm{~mm} \mathrm{Hg}$ on $60^{\circ}$ tilt with no change in cardiac rate. He had marked impairment of vagal and sympathetic cardiac reflexes. Laryngoscopy revealed no movement of his vocal cords. Tracheostomy was performed because of the risk of respiration obstruction at night due to vocal cord paralysis. A CT scan showed mild cerebral atrophy.

$B A E P S$ The responses of this patient to both monaural and binaural stimulation are shown in fig 4 . It can be seen that the overall amplitude of the responses is much reduced in comparison with a control response (fig 1). The latency of wave I on left ear and binaural stimulation were normal but
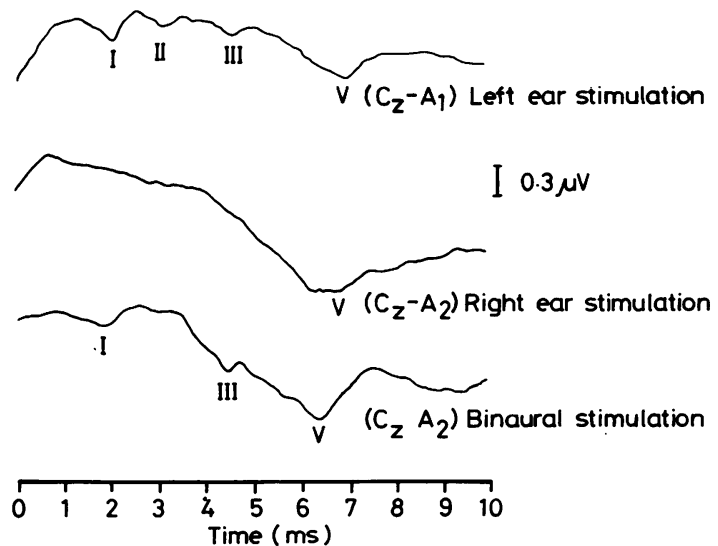

Fig 4 Brain stem responses of Case 2 (MSA (OPCA) with $P A F)$ with much reduced amplitude and bilateral delay of Wave $V$. 

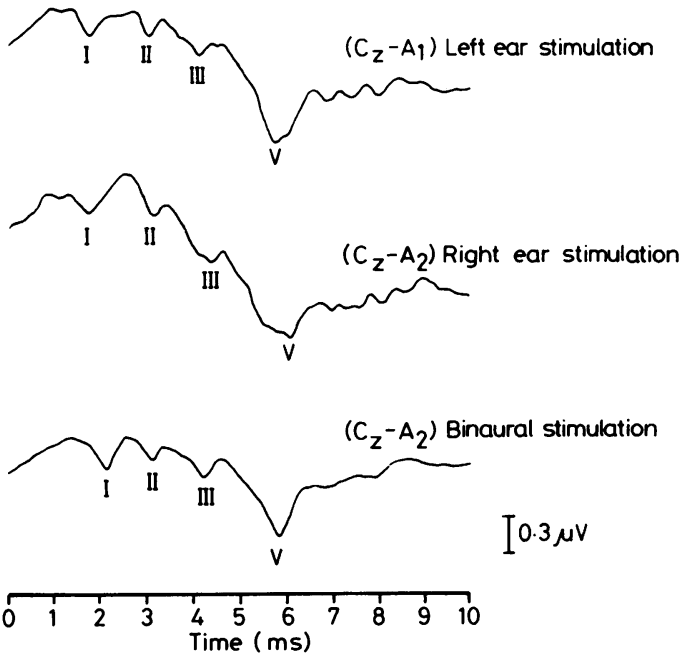

Fig 5 Brain stem responses of Case 3 (MSA with PAF) with amplitude of Wave $V$ reduced bilaterally and prolonged latency unilaterally.

the interwave interval between wave $\mathrm{I}$ and wave $\mathrm{V}$ was prolonged beyond the normal limit. The earlier components to right ear stimulation and recording were absent but wave $\mathbf{V}$ was present although delayed. In comparison with the monaural recordings the response to binaural stimulation was better defined in terms of wave structure. This raises the possibility of additional firing of binaurally activated neurons enhancing the response as at least in this case simple algebraic addition of monaural responses would not lead to an enhancement.

Conclusion Bilateral abnormalities at the level of wave $\mathrm{V}$ would appear to indicate intrinsic brain stem involvement at the pons/midbrain level.

Case 3: DW: multisystem atrophy with progressive autonomic failure

A 59-year-old surveyor presented with a 10 year history of urinary frequency with urge incontinence and impotence for about seven years. Six years previously he noticed the insidious onset of gait disturbance which, over the past years has markedly deteriorated. He noticed that his balance was poor, particularly on sudden movement, and he had several falls. There was one episode of sudden loss of consciousness. $\mathrm{He}$ had also noted impaired fine movements of his fingers, slurring his speech, mental slowing and excess salivation and dribbling.

His blood pressure was $140 / 90 \mathrm{~mm} \mathrm{Hg}$ lying but fell to $100 / 75 \mathrm{~mm} \mathrm{Hg}$ on standing. His poor gait appeared to be due to a combination of cerebellar ataxia and extrapyramidal rigidity of Parkinsonian type. There was an attitude of flexion. He was dysarthric. Convergence was limited. Facial reflexes were brisk. In the upper limbs there was bilateral rigidity with mild proximal weakness, and cerebellar ataxia on the left. In the lower limbs there appeared to be a combination of spasticity and rigidity. There was mild bilateral upper motor neuron weakness with bilateral ataxia. Tendon reflexes were uniformly brisk and both plantar responses were extensor.

Investigations Autonomic function testing showed marked impairment of sympathetic and vagal function characteristic of multiple system atrophy. The patient's blood pressure was $132 / 78 \mathrm{~mm} \mathrm{Hg}$ lying which fell to $83 / 55 \mathrm{~mm} \mathrm{Hg}$ on $60^{\circ}$ tilt. Sweating was completely absent on heat stress. Abduction of the vocal cords was normal. Visual evoked potentials were normal. The CT scan showed mild cerebral atrophy.

$B A E P S$ The brain stem potentials to both monaural and binaural stimulation are shown in fig 5 . The responses recorded from the left side with left ear stimulation were within normal limits but those recorded from the right with right ear stimulation revealed a delayed wave III.

The interval between waves I and III was prolonged beyond the normal upper limit but that between waves III and $\mathrm{V}$ was at the lower limit of normal. Wave $\mathrm{V}$ latency was just outside the upper limit of the normal range but its amplitude was significantly reduced relative to wave I. There was no enhancement of wave $\mathbf{V}$ amplitude on binaural stimulation despite the fact that the latencies of wave $\mathrm{V}$ on monaural stimulation were close to each other. In a normal subject, wave $\mathrm{V}$ amplitude increases on binaural stimulation by an average of $67 \%$ (22) compared to the monaural amplitude. The absence of any enhancement of wave $\mathrm{V}$ amplitude in this patient may indicate involvement of the region of bilateral innervation which first occurs at the level of the trapezoid body. The slowing of conduction of the input (from the right ear) from this region (indicated by a delayed wave III) may be partly responsible for the lack of enhancement of wave $V$ amplitude as it is difficult to say how a distorted input to the generator of wave $\mathrm{V}$ may influence it. Conclusion The brain stem responses of this patient show reduced amplitude of wave $\mathrm{V}$ bilaterally and prolonged
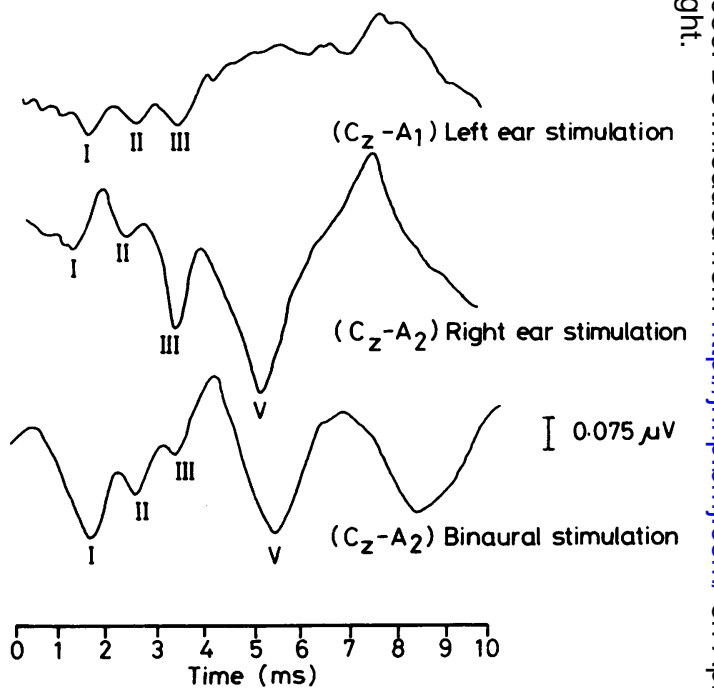

Fig 6 Brain stem responses of Case 4 (MSA with PAF) with absence of Wave $V$ in the presence of Waves I, II and III on left ear stimulation and normal response on right ear stimulation. 
latency unilaterally indicating bilateral involvement at the pons/midbrain level which is more severe on the right.

Case 4: JW: multisystem atrophy with progressive autonomic failure

A 64-year-old man presented with a four year history of difficulty with micturition and urge incontinence. A prostatectomy was performed but this aggravated his incontinence. Over the past three years his balance has steadily worsened and in the last year he has been unable to walk more than 20 or 30 yards without a rest. In the last 9 months his speech has become slurred and his writing less legible.

The patient had an expressionless face and dysarthric speech. His gait was of an extrapyramidal variety in that he tended to shuffle along and at times lurched ahead of the centre of gravity. There was bradykinesia in the limbs. The lower limb reflexes were brisk, the right plantar extensor, the left equivocal. There was a spastic increase of tone in his left leg.

Investigations His blood pressure was $154 / 104 \mathrm{~mm} \mathrm{Hg}$ lying and $128 / 94 \mathrm{~mm} \mathrm{Hg}$ standing. Autonomic function tests revealed impairment of both vagal and sympathetic cardiac reflexes.

$B A E P$ The brain stem potentials recorded from this patient are shown in fig 6 . It will be observed that the finding of significance is the absence of wave $\mathrm{V}$ on left recording with left ear stimulation. Waves I, II and III are clearly present although much reduced in amplitude in comparison with stimulation of the right ear. There was no significant difference in the hearing level between the two ears. The responses to right ear stimulation were entirely normal but those to binaural stimulation revealed no enhancement of wave $\mathrm{V}$ amplitude. The central conduction time between wave I and III was within normal limits bilaterally.

Conclusion A complete absence of wave $\mathrm{V}$ in the presence of waves I, II and III suggests a disruption of the pathway at the level of upper pons or mid brain. This is the only patient
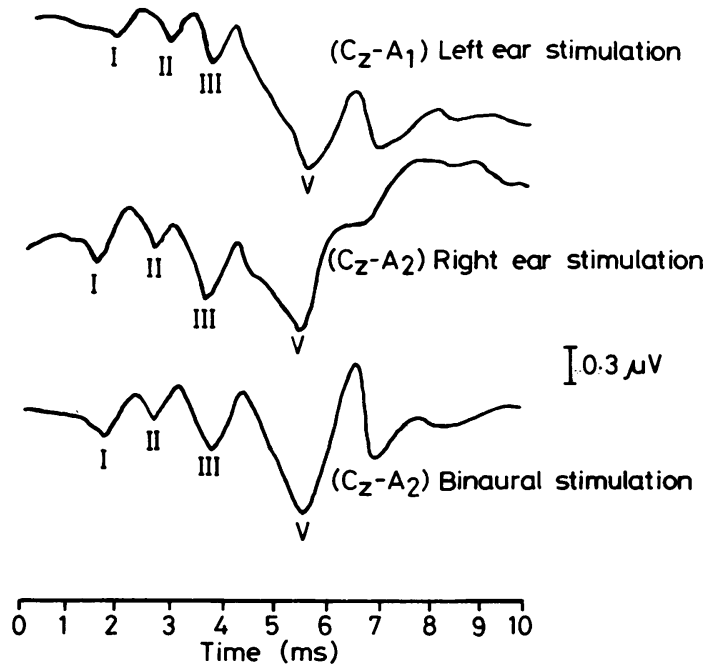

Fig 7 Brain stem responses of Case 5 (PAF) were normal in amplitude and latency. of the 14 tested to show a completely unilateral abnormality.

\section{Case 5: AC: Progressive autonomic failure}

Two years prior to admission, this 56-year-old lady developed attacks of transient light headedness which occurred only on standing or walking. Over the previous six months her attacks were occurring once or more a day; on three occasions she lost consciousness without any warning.

No abnormal signs were found on neurological examination. Her blood pressure was $125 / 70 \mathrm{~mm} \mathrm{Hg}$ supine falling rapidly to $60 / 30 \mathrm{~mm} \mathrm{Hg}$ on standing and associated with a mild tachycardia.

Investigations On body heating no sweating was observed in the lower limbs although it was profuse in the upper limbs, trunk and abdomen on elevation of temperature to $38 \cdot 8^{\circ} \mathrm{C}$. Autonomic function tests showed an impairment of peripheral sympathetic vasoconstriction and mild impairment of cardiac vagal reflexes. These tests were characteristic of progressive autonomic failure.

$B A E P S$ Normal brain stem potentials were recorded on both monaural and binaural stimulation. No latency or amplitude abnormalities were detected. These responses are shown in fig 7 .

\section{Case 6: WP: Parkinson's disease}

This 63-year-old man first presented with shaking of the right leg on resting. He had, for the last year, been aware of a tremor of the right hand when tired or under stressful conditions.

He had a slightly stooped posture, failed to swing his right arm when walking and had a striking, coarse, $6 \mathrm{~Hz}$ resting tremor of the right hand when walking. He had extrapyramidal rigidity with cogwheeling at the right wrist, slight slowness of fine finger movements on the right and a right sided rhythmical tremor affecting the right hand and leg particularly the quadriceps muscle.

$B A E P S$ Normal responses to both monaural and binaural stimulation were recorded bilaterally (fig 8).

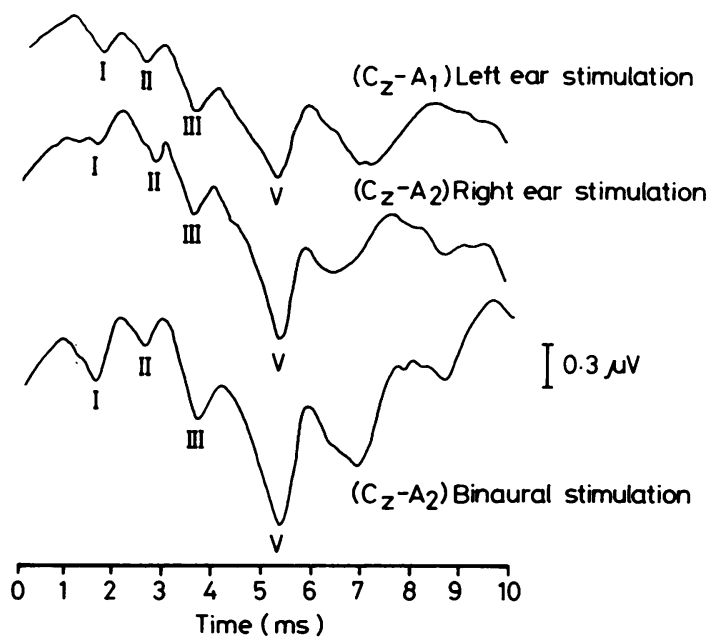

Fig 8 Brain stem responses of Case 6 (PD) were normal bilaterally on both monaural and binaural stimulation. 


\section{Discussion}

This study has demonstrated that the brain stem potentials are virtually always abnormal in patients with multisystem atrophy with progressive autonomic failure (Shy-Drager syndrome) in contrast to the normal findings in a majority of patients with Parkinson's disease and the closely associated group of patients with only progressive autonomic failure.

In about one third of patients eventually proving to have multisystem atrophy with progressive autonomic failure the wrong diagnosis is made initially (Parkinson's disease, or Parkinson's disease with progressive autonomic failure, or progressive autonomic failure) and after some years the development of more obvious clinical features enables a correct diagnosis to be made. Multisystem atrophy of the Shy-Drager type is rare but it has extrapyramidal features closely resembling either idiopathic Parkinsonism or a late onset cerebellar degeneration. ${ }^{22} 23$ Making the correct diagnosis is important because specific treatment is sometimes possible and the prognosis of each syndrome is very different. Multisystem atrophy patients have five years' mean survival time from diagnosis whereas Parkinson's patients have a nearly normal life span. The use of BAEPs should make it possible to make the correct diagnosis at an earlier stage.

Table 2 shows the widespread pathological changes described in multisystem atrophy with progressive autonomic failure, in Parkinson's disease and those observed in progressive autonomic failure alone. The description of a number of cases of progressive autonomic failure with close clinical relationship to Parkinson's disease $\mathrm{e}^{2425}$ and others with a more widespread neurological disorder has led to the consideration of two separate syndromes. ${ }^{2627}$ Pathological changes confirm this distinction; in progressive autonomic failure alone or with Parkinson's disease, Lewy bodies are detected and degenerative changes in the substantia nigra and locus coeruleus have been found. In Parkinson's disease the pathological changes also occur in the caudate nucleus and putamen. In multisystem atrophy with progressive autonomic failure, abnormalities are much more widespread including the inferior olivary nucleus, cerebellum, pons, substantia nigra, locus coeruleus, putamen and globus pallidus. In multisystem atrophy with progressive autonomic failure the striato-nigral degeneration occurs without the presence of Lewy bodies. ${ }^{27}$ It is of interest that in one previous report of three patients with olivo-pontocerebellar atrophy ${ }^{28}$ in whom no specific tests of autonomic function were reported, similar brain stem response abnormalities were detected. In this study no distinction has been made between multisystem atro- phy with or without olivo-ponto-cerebellar atrophy.

In the majority of the patients with multisystem atrophy with progressive autonomic failure the earlier components (wave I and II) of the brain stem response remained relatively unaffected in comparison with waves III and V which were both affected indicating abnormalities at the level of the pons and midbrain. The overall amplitude of the responses from these patients was reduced by about $50 \%$ with the amplitude of wave $\mathrm{V}$ relative to wave $\mathrm{I}$ being affected in 13 of the 14 patients and absence of enhancement of wave $\mathbf{V}$ on binaural stimulation in nine of the 14 patients. It is possible that cell loss and consequent transneuronal degeneration and asynchronous firing of impulses may account for the distorted wave morphology, overall reduction in amplitude and prolongation of interwave intervals.

With regard to the findings in patients with Parkinson's disease, our results are different from those of Gawel $e a^{15}$ who reported a significant delay in the mean latency of wave $\mathrm{V}$ for the Parkinson's patients in comparison with a group of normals. However, Gawel et $a^{15}$ did not specify the age range of their control group giving rise to the possibility of the result being due to a comparison between two groups of different ages. This is also considered as a possible explanation by Halliday ${ }^{29}$ for the delay reported by Gowel et al. ${ }^{15}$ Tsuji et al $^{16}$ and Chiappa ${ }^{17}$ also found no abnormalities of BAEPs in patients with Parkinson's disease.

The present study has shown that in patients with progressive autonomic failure alone the brain stem responses are normal despite the common involvement in multisystem atrophy with progressive autonomic failure of brain stem nuclei coordinating autonomic reflexes such as locus coeruleus, dorsal vagal nucleus and tractus solitarius most of which are monoaminergic. The dorsal vagal nucleus and the nucleus ambiguous degenerate both in progressive autonomic failure and multisystem atrophy with progressive autonomic failure in the medulla close to the site of the generator of wave II which is the cochlear nucleus. Therefore, with a sufficiently large lesion the possibility exists of a coincidental interruption of the auditory pathway in the medulla. However, in the absence of any abnormality of the brain stem response it is postulated that the involvement in progressive autonomic failure of the dorsal vagal nucleus and nucleus ambiguous is restricted to these nuclei.

Figure 9 illustrates the auditory pathway and the nuclei and tracts in the brain stem involved in multiple system atrophy with progressive autonomic failure. From the abnormalities of the brain stem response in patients with multisystem atrophy with progressive autonomic failure, it is clear that some 


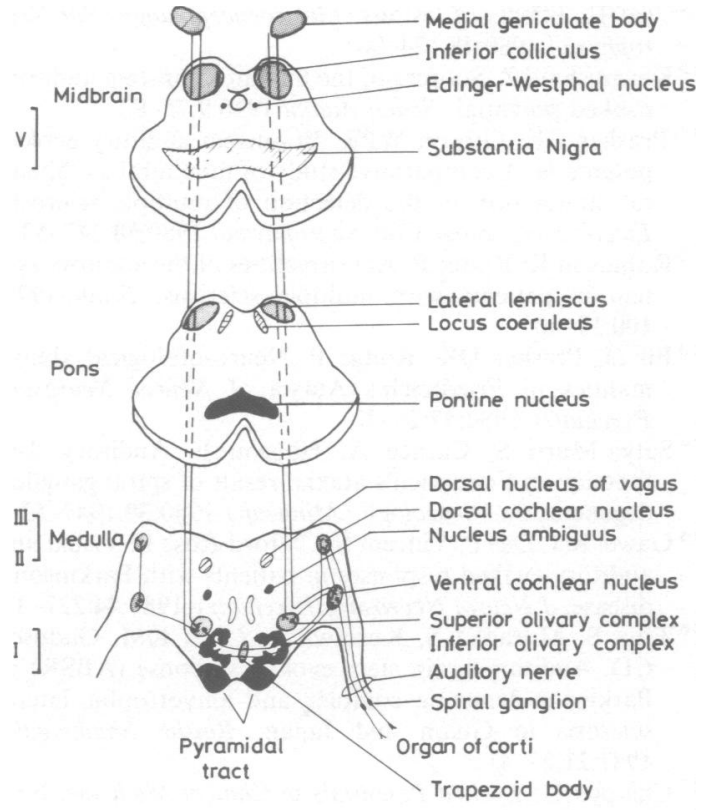

PAF
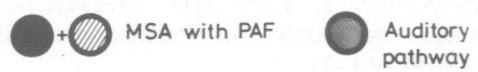

Fig 9 Diagram showing sites involved in PAF alone which clearly do not affect the BAEP. As these sites, which involve central autonomic control are also affected in $P A F$ with $M S A$ it is necessary to exclude the sites common to both syndromes. Therefore by subtraction, the remaining sites in which degeneration is exclusive to the MSA component of the syndrome may be obtained. The auditory pathways are also shown with the Roman numerals indicating the generator sites of the brain stem potentials. disruption of the auditory pathway occurs at the level of the pons as in nearly all of these patients there is a significant delay or reduction in the components of the response generated beyond this region. On the basis of the generator sites for the various brain stem response components and the anatomical proximity of the regions involved in the auditory pathway and multisystem atrophy with progressive autonomic failure the most likely area of disruption along the auditory pathway is in the region of the superior olivary complex, which is described by Ranson and Clark ${ }^{30}$ as "a small mass of grey matter located in the ventrolateral part of the reticular formation of the pons in close relation to the trapezoid body and not far from the rostral pole of the inferior olivary nucleus". This description is significant as the evidence of necropsy cases cited by Oppenheimer ${ }^{31}$ shows the inferior olivary nucleus to be one of the sites of degeneration in multisystem atrophy with progressive autonomic failure. It is difficult to speculate how the inferior olivary nucleus, which forms a broad and irregular conspicuous section of the medulla, may affect the superior olivary complex in its degenerative process. The best evidence on the neuropathology of progressive autonomic failure is cited by Oppenheimer ${ }^{31}$ who, in reviewing the cases in the literature showed that of the 10 cases of progressive autonomic failure alone, only one had cell loss in the inferior olivary nucleus. The brain stem responses in progressive autonomic failure alone appear to be in keeping with this finding. Of the 41 cases of multisystem atrophy with progressive autonomic failure, 30 had cell loss in the inferior olivary nucleus. Thus, it appears that the most likely common area responsible for the abnormalities of the brain stem responses observed in patients with multisystem atrophy with progressive autonomic failure is

Appendix Brain stem auditory evoked potentials

\begin{tabular}{|c|c|c|c|c|c|c|c|c|c|c|c|}
\hline & \multicolumn{6}{|c|}{ Latency (ms) } & \multicolumn{5}{|c|}{ Amplitude of Wave $V(\mu V)$} \\
\hline & \multicolumn{2}{|c|}{ Wave I } & \multicolumn{2}{|c|}{ Wave III } & \multicolumn{2}{|c|}{ Wave V } & \multicolumn{2}{|c|}{ Absolute } & \multicolumn{2}{|c|}{$\begin{array}{l}\text { Ratio of Wave V } \\
\text { Relative to Wave I }\end{array}$} & \multirow{2}{*}{$\begin{array}{l}\text { Ratio of Max } \\
\text { Binaural/Max } \\
\text { Monaural } \\
\text { amplitude of Wave }\end{array}$} \\
\hline & $R R$ & $L L$ & $R R$ & $L L$ & $R R$ & $L L$ & $R R$ & $L L$ & $R R$ & $x^{2}+x^{2}$ & \\
\hline $\begin{array}{l}\text { DG } \\
\text { TR } \\
\text { DW } \\
\text { FF } \\
\text { GS } \\
\text { DE } \\
\text { PP } \\
\text { BA } \\
\text { MW } \\
\text { KP } \\
\text { LA } \\
\text { JW } \\
\text { JM } \\
\text { DR }\end{array}$ & $\begin{array}{l}1.61 \\
1.70 \\
1.40 \\
1.63 \\
1.42 \\
1.62 \\
1.68 \\
1.50 \\
1.64 \\
1.68 \\
1.71 \\
1.43 \\
1.57\end{array}$ & $\begin{array}{l}1.84 \\
1.80 \\
1.77 \\
1.42 \\
1.53 \\
1.55 \\
1.77 \\
1.75 \\
1.86 \\
1.64 \\
1.60 \\
1.59 \\
1.64 \\
1.57\end{array}$ & $\begin{array}{l}3.92 \\
4 \cdot 40 \\
3 \cdot 93 \\
3.63 \\
3 \cdot 40 \\
3 \cdot 69 \\
3 \cdot 97 \\
3.97 \\
3 \cdot 33 \\
4 \cdot 11 \\
3 \cdot 52 \\
\overline{3.88}\end{array}$ & $\begin{array}{l}3 \cdot 92 \\
4 \cdot 50 \\
4 \cdot 07 \\
3 \cdot 33 \\
3.68 \\
3 \cdot 52 \\
\overline{4 \cdot 19} \\
\overline{3 \cdot 20} \\
4 \cdot 46 \\
3 \cdot 44 \\
\frac{3}{3 \cdot 88}\end{array}$ & $\begin{array}{l}5.84 \\
6 \cdot 74 \\
6 \cdot 15 \\
6 \cdot 42 \\
\overline{6.33} \\
7.23 \\
5 \cdot 78 \\
5.72 \\
5 \cdot 25 \\
5 \cdot 42 \\
\frac{5}{5 \cdot 84}\end{array}$ & $\begin{array}{l}6 \cdot 92 \\
7 \cdot 00 \\
5 \cdot 75 \\
5 \cdot 37 \\
6 \cdot 23 \\
6 \cdot 25 \\
7 \cdot 00 \\
6 \cdot 10 \\
5 \cdot 64 \\
5 \cdot 18 \\
- \\
6 \cdot 16 \\
5 \cdot 91\end{array}$ & $\begin{array}{l}0.27 \\
0.24 \\
0.30 \\
0.03 \\
\overline{0.09} \\
0.15 \\
0.11 \\
0.12 \\
0.27 \\
\overline{0.34} \\
\overline{0.22}\end{array}$ & $\begin{array}{l}0.15 \\
0.17 \\
0.45 \\
0.60 \\
0.18 \\
0.30 \\
0.18 \\
0.45 \\
0.17 \\
0.54 \\
- \\
\overline{0} \\
0.12\end{array}$ & $\begin{array}{l}1.10 \\
0.90 \\
2.50 \\
\overline{0.30} \\
0.40 \\
0.57 \\
0.75 \\
1.40 \\
\overline{3.40} \\
\overline{1.00}\end{array}$ & $\begin{array}{l}1.50 \\
0.70 \\
3.00 \\
0.20 \\
0.90 \\
3.20 \\
0.60 \\
2.66 \\
1.41 \\
1.80 \\
- \\
\overline{0.70} \\
0.40\end{array}$ & $\begin{array}{l}1.00 \\
1.09 \\
0.66 \\
0.10 \\
1.27 \\
1.42 \\
0.40 \\
0.33 \\
0.90 \\
1.60 \\
- \\
0.67 \\
0.41 \\
0.83\end{array}$ \\
\hline
\end{tabular}

Key: - = Wave absent or undefined. 
the ponto-medullary region involving both the superior and the inferior olivary nuclei.

In conclusion, this study provides, by the recording of brain stem auditory evoked potentials, a noninvasive means for differential diagnosis between progressive autonomic failure alone or with Parkinson's disease, and progressive autonomic failure with multisystem atrophy (Shy-Drager syndrome). Although these conditions are different pathological entities with distinct histological appearances, their clinical separation in the early stages is often difficult, if not impossible because of overlapping clinical features. Any additional information in this respect is very valuable in the differential diagnosis. Patients and their relatives need to know as accurate a diagnosis as possible because it affects both treatment and prognosis. The prognosis of multisystem atrophy with progressive autonomic failure is so much worse than progressive autonomic failure alone or with Parkinson's disease. Brain stem auditory evoked potentials, by providing that additional information, may help clarify the diagnosis in patients with either apparent Parkinson's disease and unusual features who may or may not have multisystem atrophy as well as patients presenting with apparent pure progressive autonomic failure alone. As far as the authors are aware, there are no other closely related neurological conditions in which the BAEP dissociates so clearly between important differential diagnoses.

\section{References}

${ }^{1}$ Jewett DL, Williston JS. Auditory evoked far fields averaged from the scalp of humans. Brain 1971;94:681-96.

${ }^{2}$ Buchwald FS, Huang CH. Far field acoustic response: origins in the cat. Science 1975;189:382-4.

${ }^{3}$ Huang CM, Buchwald JS. Interpretation of the vertex short latency acoustic response: A study of single neurons in the brain stem. Brain Res 1977;137:291-303.

${ }^{4}$ Stockard JJ, Rossiter VS. Clinical and pathological correlates of brain stem auditory response abnormalities. Neurology (Minneap) 1977;27:316-25.

${ }^{5}$ Sohmer H, Feinmesser M, Szabo G. Sources of electrocochleographic responses as studied in patients with brain damage. Electroencephalogr Clin Neurophysiol 1974;37:663-9.

${ }^{6}$ Starr A, Achor LJ. Auditory brainstem responses in neurological disease. Arch Neurol 1975;32:761-8.

${ }^{7}$ Starr A, Hamilton AE. Correlation between confirmed sites of neurological lesions and abnormalities of farfield auditory brainstem responses. Electroencephalogr Clin Neurophysiol 1976;41:595-618.

${ }^{8}$ Britt RH, Rossi GT. Neural generators of brain stem auditory evoked responses. Part I. Lesion studies. Neuroscience Abstracts 1980;6:594.

${ }^{9}$ Achor LJ, Starr A. Auditory brainstem responses in the cat II. Effects of lesions. Electroencephalogr Clin Neurophysiol 1980;48:174-90.

${ }^{10} \mathrm{Kevanishvili} \mathrm{Z}$. Sources of the human brainstem auditory evoked potential. Scand Audiol 1980;9:75-82.

${ }^{11}$ Prasher DK, Gibson WPR. Brainstem auditory evoked potentials. A comparative study of monaural vs. binaural stimulation in the detection of multiple sclerosis. Electroencephalogr Clin Neurophysiol 1980;50:247-53.

${ }^{12}$ Robinson K, Rudge P. Abnormalities of the auditory system in patients with multiple sclerosis. Brain 1977; 100:19-40.

${ }^{13}$ Ell JJ, Prasher DK, Rudge P. Neuro-otological abnormalities in Friedreich's Ataxia. J Neurol Neurosurg Psychiatry 1984;47:26-32.

${ }^{14}$ Satya-Murti S, Cacace A, Hanson P. Auditory dysfunction in Friedreich's ataxia: result of spiral ganglion degeneration. Neurology (Minneap) 1980;30:1047-53.

${ }^{15}$ Gawel MJ, Das P, Vincent S, Clifford Rose F. Visual and auditory evoked responses in patients with Parkinson's disease. J Neurol Neurosurg Psychiatry 1981;44:227-32.

${ }^{16}$ Tsuji S, Muraoka S, Kuroiwa Y, Chen KM, Gadusck CD. Auditory brain stem evoked response (ABSR) of Parkinson-dementia complex and amyotrophic lateral sclerosis in Guam and Japan. Rinsho Shinkeigaku 1981;21:37-41.

${ }^{17}$ Chiappa K. Evoked Potentials in Clinical Medicine. New York: Raven Press, 1983.

${ }^{18}$ Bodis-Wollner I, Yahr MD. Measurements of visua evoked potentials in Parkinson's disease. Brain 1978;101:661-71.

${ }^{19}$ Yaar I. The effect of Levodopa treatment on the visuaki evoked potentials in Parkinsonian patients. Electroencephalogr Clin Neurophysiol 1980;50:267-4.

${ }^{20}$ Ehle AL, Stewart M, Lellelid NE, Leventhal NA. Normaß checkerboard pattern reversal evoked potentials in Par kinsonism. Electroencephalogr Clin Neurophysiof 1982;54:336.

${ }^{21}$ Prasher DK, Sainz M, Gibson WPR. Binaural voltage summation of brainstem auditory evoked potentials: An adjunct to the diagnostic criteria for multiple sclerosis. Ann Neurol 1981;11:86-91.

${ }^{22}$ Shy GM, Drager GA. A neurological syndrome associated with orthostatic hypotension. Arch Neurol 1960;2:511-27.

${ }^{23}$ Bannister R, Oppenheimer DR. Degenerative diseases of the nervous system associated with autonomic failure. Brain 1972;95:457-4.

${ }^{24}$ Bannister R, Ardill L, Fentem P. Defective autonomic control of blood vessels in idiopathic orthostatic hypotension. Brain 1967;90:725-46.

${ }^{25}$ Thomas JE, Schirger A. Idiopathic orthostatic hypotension: A study of its natural history in 57 neurologically affected patients. Arch Neurol 1970;22:289-93

${ }^{26}$ Graham JG, Oppenheimer DR. Orthostatic hypotension and nicotine sensitivity in a case of multiple system atrophy. J Neurol Neurosurg Psyschiatry 1969;32:28-34.

${ }^{27}$ Spokes EGS, Bannister R, Oppenheimer DR. Multiple system atrophy with autonomic failure. Clinical, Histological and Neurochemical observations of four cases. $J$ Neurol Sci 1979;43:59-82.

${ }^{28}$ Gilroy J, Lynn GE. Computerised tomography and auditory evoked potentials. Use in the diagnosis of 
olivo-ponto-cerebellar degeneration. Arch Neurol 1978;35:143-7.

${ }^{29}$ Halliday AM. Evoked Potentials in Clinical Testing. Churchill Livingstone, Edinburgh, 1982.

${ }^{30}$ Ranson SW, Clark SL. Anatomy of the Nervous System.
WB Saunders and Co., 1953:185-208.

${ }^{31}$ Oppenheimer DR. Neuropathology of progressive autonomic failure. In: Sir Roger Bannister, ed. Autonomic Failure. Oxford University Press, 1983:267-83. 